\title{
PATERNALISMO Y BIEN COMÚN
}

1 término «paternalismo» es ya peyorativo. Suele referir a un cierto tipo de protección o ayuda no justificado. No obstante, hay casos en los que no es sólo lícito, sino una obligación el proteger o ayudar. Me propongo aquí aportar algunas ideas para aclarar la distinción entre el paternalismo justo y el injusto. La misma definición de paternalismo es un caso de ambivalencia. Consta de una parte negativa y otra positiva. Es paternalista: 1) la acción de inmiscuirse en la libertad de otra persona, 2) con la intención de defender su bien.

No creo que sea un disparate asociar ambas partes de tal definición con la distinción hecha por Isaiah Berlin entre libertad negativa y libertad positiva. Cabría decir que es paternalista la acción de coartar la libertad negativa con el fin de hacer viable la positiva. Veámoslo despacio. Es sabido que la libertad negativa alude, según Berlin, a la posibilidad de actuar sin intervención ajena, mientras que la positiva significa el poder de decidir por uno mismo o -como ha notado certeramente Alfonso Ruiz Miguel- la posibilidad de querer con autonomía. Las libertades negativas son las libertades cívicas. La positiva es la capacidad de autogobernarse, la participación real en la elaboración de las normas jurídicas y sociales. Libertad de coacción y libertad para querer, decidir, pensar, actuar. Ser libre en el sentido positivo quiere decir ser plenamente sujeto y no objeto, plenamente fin y no sólo medio para los demás. Spinoza, Kant o Stuart Mill son claros defensores de tal forma de libertad.

Es precisamente la libertad positiva, la libertad sin reservas, la que el propio Berlin contempla con mayor escepticismo, reconociendo la dificultad que entraña llevarla a la práctica. Es difícil, incluso, defenderla teóricamente sin caer en contradicciones. Porque es una libertad que supone saber, discernimiento de lo que debe ser, de los valores adecuados, de lo que hay que preferir y querer. La posibilidad de decidir es, en primer lugar eso: posibilidad material, estar en posesión de unos requisitos indispensables. 
Sin embargo, éstos son, a su vez, condición necesaria pero no suficiente. Pues la libertad positiva no es sólo posibilidad de, es también capacidad, habilidad para decidir, querer o hacer sabiamente. Gozar de libertad positiva consiste en ser competentes en tanto seres libres.

La libertad así entendida, como competencia para elegir bien, por complicada y difícil que parezca, es un ideal que no debe ignorarse si no queremos quedarnos con una noción «excesivamente liberal» de libertad, que es la que nos brinda la libertad negativa. Libertad como un simple «dejar hacer», que no atiende a los muchos y variados impedimentos para la plena autonomía. Berlin cuida de señalar que no debe confundirse la coacción o intervención con la debilidad o incompetencia, con la incapacidad física o psíquica. La libertad -dice- no debe ser confundida con la igualdad o la justicia, la cultura, la riqueza o la conciencia tranquila. Si la libertad de unos depende de la miseria de los otros, el sistema es injusto. La pérdida de la libertad de aquéllos tal vez producirá mayor justicia, pero no producirá mayor libertad. Observación la de Berlin perfectamente aceptable al tratarse -como es el caso- de la libertad negativa, pero que no vale para la positiva. Ahí, capacidad o competencia y libertad son difícilmente separables. No sólo la debilidad o la incompetencia, del orden que sean, incapacitan para el autogobierno: éste, la libertad positiva, queda bien definida como competencia para elegir, es decir, como saber elegir. Por ello, y volviendo al tema del paternalismo, hemos de preguntarnos hasta qué punto es lícito restringir la libertad negativa -impedir o inmiscuirse en ciertas acciones- a fin de educar y adiestrar en el ejercicio de la libertad positiva. Hasta qué punto es lícita la coacción dirigida a garantizar la igualdad de oportunidades. Hasta qué punto, en definitiva, la justa realización de la democracia -autogobierno- implica la servidumbre a una voluntad general.

Aceptemos la distinción de Nietzsche según la cual el mundo lo componen dos tipos de personas: los fuertes y los débiles. Sin que por ello tengamos que suscribir al mismo tiempo la inadmisible moral nietzscheana. Los fuertes, si lo son en el sentido pleno y «moral» de la palabra, tendrán que subordinar la libertad al deber. La virtud de la fortaleza nunca ha podido alejarse demasiado de la de la temperancia: hay que preferir lo preferible, optar por la dignidad, luchar por lo que merece ser defendido. En cuanto a los débiles, no puede serles negada la libertad ni, por tanto, la dignidad que es premisa de aquélla. Dicho de otra forma, las instituciones deberán proteger al débil, al incompetente, al incapaz de ejercer dignamente su libertad. Deberán hacerlo 
competente. Del mismo modo que hemos identificado la libertad positiva y la competencia para elegir sabiamente, llamamos ahora incompetente, incapaz de ser libre al débil de ánimo, al disminuido físico o psíquico, al desposeído. Son débiles los niños, los enfermos, los pobres, los delincuentes, los drogadictos. Si la definición del paternalismo habla de una restricción de la libertad del otro con la intención de proporcionarle un bien, entiendo, pues, que se trata de restringir la libertad negativa para educar en la positiva. Convertir al incompetente en competente. Ahora bien, la legitimación de tal tipo de acción pasa por una adecuada comprensión de la competencia.

El paternalismo en principio y por definición se autojustifica: se limita la libertad de alguien con vistas a su bien. Lo cual permite suponer que ciertas personas poseen un saber o competencia que les autoriza a intervenir en una felicidad que no es la suya. Fue precisamente esa segunda parte justificativa la que condenó Stuart Mill rechazando a su vez cualquier forma de paternalismo. Recordemos la célebre cita: «El único fin que autoriza a la humanidad, individual o colectivamente, a intervenir en la libertad de otros, es la autoprotección. El único propósito que permite ejercer correctamente el poder sobre cualquier miembro de la comunidad civilizada, contra su voluntad, es prevenir el daño a otros. En su propio bien, físico o moral, no es motivo suficiente.»

Pero ahí Stuart Mill exagera o no distingue con precisión suficiente. Si aceptamos como una realidad que hay personas débiles, necesitadas de protección, no sólo en el sentido negativo -protección del posible daño ajeno-, sino en el positivo -protección para actuar-, hemos de admitir también la licitud de un cierto paternalismo. El que, efectivamente, busca y va dirigido al bien del otro. Conviene aclarar, pues, de inmediato, qué es el bien del otro, quién lo decide o conoce, si se trata del bien de un individuo o puede hablarse asimismo del bien de la sociedad.

La misma distinción entre fuertes y débiles nos da la primera respuesta. El competente es el fuerte, el superior en cualquier de los sentidos posibles: cronológico, cultural, político, económico, religioso, profesional. A partir de esa realidad -de la superioridad de unos sobre otros- las sociedades han ido estableciendo y sancionando una serie de relaciones: amo y siervo, gobernante y gobernado, padre e hijo, profesor y discípulo, clérigo y fiel, médico y enfermo, y tantas otras de carácter parecido. A ciertos propósitos, ésas son, en efecto, relaciones de competencia-incompetencia. 
Pero sólo a ciertos propósitos. Los locos, los delincuentes, los niños, los pobres, los enfermos son incompetentes en determinadas circunstancias, cuando actúan como tales, pero no en cualquier caso.

Este es, a mi juicio, el punto importante y fundamental para aclarar el concepto de competencia que aquí interesa. La relación entre competencia y paternalismo nos permitirá distinguir entre el paternalismo justo y el injusto, de acuerdo con los siguientes criterios.

1. No hay propiamente paternalismo, porque se trata de un paternalismo justificado, cuando existe un deber de protección al otro. El tal deber hace suponer que uno sabe cuál es el bien del otro, qué le conviene. No sólo lo sabe, sino que tiene la obligación de saberlo y procurarlo. Tiene unas obligaciones con respecto al otro. Pensemos en relaciones como las que dan o deben darse entre padres e hijos, profesores y alumnos, gobernantes y gobernados, médicos y enfermos. En todas ellas, hay un deber de protección y asistencia, que, en la mayoría de los casos, conlleva un recorte de la libertad del otro, pero un recorte justificado puesto que quien lo hace conoce de veras -o debería conocer dada su especial condición- el bien del otro.

2. Hay «paternalismo», en el sentido peyorativo, común, no justificable, del término, cuando bajo la apariencia de que se está protegiendo a un individuo o grupo, de hecho se está persiguiendo el propio bien, defendiendo el propio interés. Bajo el nombre del bien común, quiere imponerse una cierta ideología. En tal caso, la relación entre competencia e incompetencia desaparece porque no la hay. El paternalista se está atribuyendo un saber, un poder y unas capacidades que no tiene en absoluto. Y, por lo mismo, atribuye al otro una incompetencia igualmente desprovista de fundamento. Pienso en casos como el de la «protección» a un hijo ya mayor de edad, la imposición por parte del médico o el capellán de sus convicciones sobre, por ejemplo, la eutanasia, la prohibición oficial del juego por parte del Estado con el fin de «proteger» a los pobres. Todos aquellos casos en los que la ayuda o protección ha de entrecomillarse, porque no hay razones obvias para hacerlo: huele a chamusquina, a engaño, a manipulación el interés real que se está defendiendo.

Ahora bien, distinguir en la práctica el paternalismo justificado del que no lo es, entre la competencia fundamentada y la autoatribuida sin fundamento, entre la promoción de un bien real y la de un sospechoso «bien común», es más complicado. Dworkin y Murphy, en sendos escritos, nos orientan sobre posibles criterios. Según Dworkin, «el paternalismo sólo se justifica 
si preserva una mayor libertad para el individuo». Murphy es algo más explícito cuando dice que «el paternal ismo se justifica en aquellos casos en que los bienes primarios están en peligro grave o irreversible, y no en otros casos». Es precisamente esa idea de «bienes primarios» la que quiero utilizar para echar algo más de luz en el problema de la competencia.

Creo que una buena definición del incompetente, débil, inhábil, en el sentido en que aquí interesa, es a que lo identifica con el que no sabe o no puede procurarse por sí mismo los bienes primarios básicos, para lo cual necesita ayuda parcial o total. Es el caso, otra vez, del niño, el enfermo o el analfabeto, el caso de quienes carecen de uno o varios de los bienes reconocidos como fundamentales para sobrevivir con dignidad y poder hacer uso de la libertad. La salud, la vivienda, el trabajo, la educación son condiciones sin las cuales la vida humana como tal no llega a realizarse. Quien no posee ni tiene acceso a tales bienes, es, en la medida en que le faltan, débil e incompetente.

Proporcionar los bienes básicos -o los medios para acceder a ellos- a los desposeídos, es el primer deber de justicia. Un deber, pues, individual, pero que debe ser regulado colectivamente. Un deber individual en la medida en que es social y es político. Compete al Estado y a las instituciones hacerse cargo del problema y subsanar los desequilibrios. De entre los teóricos contemporáneos de la política, Rawls es, sin duda, quien más se ha acercado a la formulación de unos principios mínimamente concretos de justicia distributiva: el principio de igualdad de oportunidades, y el llamado «principio de la diferencia», el cual admite las desigualdades sociales y económicas siempre que éstas estén ordenadas y dirigidas hacia el beneficio del más desprotegido. Es decir, conviene distribuir desigualmente los bienes precisamente para favorecer al menos competente. Todavía, según Rawls, y quizá con un exceso de optimismo, la instauración y la puesta en práctica de los principios de justicia irá produciendo en los ciudadanos algo así como un hábito de la justicia. De tal forma que, tanto institucional como individualmente, la sociedad será cada vez más justa.

Si esto fuera cierto, si la teoría rawlsiana se hiciera realidad, nada de lo que ella postula sería paternalismo en el sentido negativo del término. Al contrario, se trata de obligaciones políticas y sociales dirigidas a promover el bien primario y fundamental, condición necesaria para cualquier otro bien: la igualdad básica de los ciudadanos. Sólo habría que reprocharle a Rawls que coloque tales principios de la justicia en segundo lugar, después de un primer principio, que es el que proclama la igual libertad de 
todos. Si es cierto lo que aquí estoy defendiendo, esa igual libertad -negativa, pero, sobre todo, positiva-, no es viable mientras falte la igualdad básica, cuya promoción constituye, a mi juicio, la única forma de paternalismo justificado.

Dicho brevemente, el paternalismo se legitima cuando lo que busca es hacer justicia. Que el débil lo sea menos o deje de serlo. El paternalismo se justifica cuando su ejercicio promueve la distribución de los bienes primarios. Pero no se justifica cuando se inmiscuye en la distribución de otro tipo de bienes no regulables colectivamente porque depende de opciones personales no generalizables. Aquellos bienes para cuya determinación no existen profesionales ni competentes: el tipo de educación que deba darse a los hijos, el tipo de trabajo que uno desea para sí, la forma de vida que cada cual apetece. Aquellos bienes, precisamente, de cuya elección o rechazo cada cual ha de poder responder en tanto individuo libre y autónomo. El padre de familia deja de «educar», el médico deja de «sanar» cuando interviene en un asunto que ya no es de su competencia. Cuando el supuesto «bien del otro» no es ya el bien del enfermo qua enfermo o el del niño qua niño. Es, por el contrario, un supuesto «bien general», fruto de unas convicciones, unas creencias, unos intereses cuya imposición se hace aprovechando el status superior y privilegiado del padre o del médico en cuestión. Tal paternalismo no se justifica porque universaliza lo que no es universalizable, pretende elevar a la categoría de un «se debe» lo que sólo es un deber derivado de determinadas convicciones.

Para volver a la noción de libertad positiva, de donde habíamos partido, hay que decir que el paternalismo estará justificado siempre y cuando vaya dirigido a hacer posible el autogobierno. No cuando por libertad positiva o autogobierno se entienda la realización de un cierto tipo de persona o sociedad. Digamos que de lo que se trata es de que toda persona lo sea realmente, no de que se haga a imagen y semejanza de un modelo previamente determinado.

Hay ciertos ejemplos recurrentes en los estudios sobre paternalismo. Una buena parte de ellos no hace sino abundar en la trivialidad característica del uso del ejemplo en la filosofía anglosajona: si es o no paternalista la prescripción del cinturón de seguridad a los conductores de automóvil o del casco a los motoristas. Son ilustraciones que sólo ayudan a banalizar el tema. Otros ejemplos, más complejos e interesantes, son los que hacen referencia a ciertas restricciones expresas en el derecho laboral: las prohibiciones de trabajo a niños o las limitaciones del horario laboral. Asimismo, los casos concernientes a ciertos deberes 
con los marginados, procedentes de culturas distintas y supuestamente inferiores: ¿es lícito, por ejemplo, «civilizar» a los indios de los países latinoamericanos?, ¿se cuenta entre los bienes primarios cierta idea de civilización?

La respuesta a tales perplejidades, sean o no triviales, es una y la misma. Se trata de decidir en cada caso si el bien que está en cuestión ha de ser considerado como prescriptivo para todos: universalizable. Si se trata de una cuestión de justicia. Es evidente que hay que decidirse sobre cuáles son esos bienes primarios y universalizables. De lo contrario, no tiene sentido seguir hablando de derechos humanos: los derechos o los bienes de la humanidad en cuanto a tal. Sin un cierto norte, carece de perspectiva el progreso moral, la moral como tarea colectiva. Carece de perspectiva la justicia. Debe haber, realmente, un bien común, transcultural, el contenido de esa voluntad general que hace que la democracia sea mínimamente gobernable.

Tal vez la primera forma de acercamiento a ese bien común sea la negativa, la negación de todos aquellos bienes supuestamente comunes, la negación de todos los ídolos que pretenden uniformar lo que no hace ninguna falta que se uniformize ni que se iguale. El paternalismo no justificado es un engaño, una atención ilegítima al bien del otro. Es, desde luego, difícil delimitar los bienes básicos de los que no lo son. Pero sí debe decirse que sí hay y debe haber «profesionales» competentes para decidir y promover los bienes básicos, sí hay unos deberes institucionales y personales con vistas a la protección de tales bienes, la definición y precisión de los mismos -los bienes primarios- no es competencia de nadie y es, a la vez, competencia de todos. Es, sucintamente, el ejercicio de la libertad positiva. 


\section{BIBLIOGRAFÍA}

Isaiah Berlin, «Two Concepts of Liberty», en Anthony Quinton, ed., Political Philosophy, Oxford University Press, 1977.

Gerard Dworkin, «Paternalism», en R. Sartorius, ed. Paternalism, University of Minnesota Press, Mineapolis, págs. 19-34.

Jeffrie C. Murphy, Incompetence and Paternalism.

John Rawls, A Theory of Justice, Clarendon Press, Oxford, 1972.

Alfonso Ruiz Miguel, «Sobre los conceptos de la libertad», Anuario de Derecho Humanos, núm. 2, Universidad Complutense, Madrid, 1983, págs. 315-349.

John Stuart Mill, On Liberty, Collins, Glasgow, 1962. 